Revista lus et Praxis, Año 21, No 1, 2015, pp. 503 - 528

ISSN 0717 - 2877

Universidad de Talca - Facultad de Ciencias Jurídicas y Sociales

"Consideraciones sobre la determinación del monto del daño

por infracciones al derecho de autor en entornos digitales"

Karen Isabel Cabrera Peña

Trabajo recibido el 14 de julio y aprobado el 24 de noviembre de 2014

\title{
Consideraciones sobre la determinación del monto del daño por infracciones al derecho de autor en entornos digitales
}

\author{
CONSIDERATIONS OF DETERMINATION OF ECONOMIC DAMAGE \\ AMOUNT FOR COPYRIGHT INFRINGEMENT IN DIGITAL ENVIRONMENTS
}

Karen Isabel Cabrera Peña*

\begin{abstract}
RESUMEN
La tecnología ha transformado las dinámicas de creación y adquisición de obras en entornos digitales. Como consecuencia, hay nuevos casos de infracciones al derecho de autor que necesitan reglas claras sobre cómo debe determinarse el daño. Actualmente en Colombia la determinación del monto del daño en infracciones al derecho de autor en entornos digitales se basa sobre la teoría de la propiedad material en sentido tradicional que difiere a la propiedad intelectual.

El presente artículo analiza los conceptos básicos del daño y su determinación en infracciones al derecho de autor en entornos digitales a la luz de la ley colombiana, en contraste con el sistema español y estadounidense, con la finalidad de abrir un debate sobre la importancia y dificultades que se presentan actualmente en el tema.
\end{abstract}

ABSTRACT

Technological have transformed the creation and acquisition dynamics of works in digital environments. As a result, it brings along new copyright infringement scenarios that need clear rules about how the amount of damage must be determinate when an infringement occurs. Currently in Colombia, determining the amount of damages in copyright infringement in digital environments is based on the material property theory which differs in its objective compared to the intellectual property.

This article discusses the basics of the damage and now determining it in infringements of copyright in digital environments in Colombian law in contrast with the Spanish and American system in order to open a debate on the importance and the difficulties encountered in this topic.

\section{Palabras Clave}

Daño, Derecho de autor, Entornos digitales

\section{KEYWORDS}

Damage, Copyright, Digital environments

* Candidata a doctora en Derecho de la Universidad del Rosario, Colombia, y Visiting Scholar del Washington College of Law program en American University, Estados Unidos. Correo electrónico: kicabrerap@gmail.com.

La autora agradece a Alberto Cerda por su paciencia y orientación en la realización de este artículo. 


\section{Introducción}

El derecho de autor es la rama de la propiedad intelectual conformada por prerrogativas de carácter patrimonial y moral, cuyo fin es proteger obras científicas, literarias o artísticas producto del ingenio y creatividad de los seres humanos ${ }^{1}$. A su vez, busca el acceso a dichas obras para estimular la innovación y la creatividad. En los últimos años este derecho, debido a los avances de la tecnología ${ }^{2}$, ha sufrido grandes transformaciones, lo cual ha llevado a innovadoras formas de crear, conocer y adquirir las obras ${ }^{3}$.

Estas innovaciones preocupan a las autoridades por dos razones: primero, no es claro el control que debe recaer sobre la explotación de los derechos de autor; y segundo, la implementación de medidas muy restrictivas o desmesuradas puede generar desequilibrios entre los derechos económicos del autor y los derechos de la sociedad a disfrutar estos contenidos ${ }^{4}$. En relación con lo anterior, se han estipulado normas que consignan como ilícitas algunas conductas que en caso de configurarse implican que los infractores deberán reparar los daños que causen.

En cuanto a los actos constitutivos de responsabilidad civil, tanto en entornos tradicionales como digitales ${ }^{5}$, la normatividad legal, si bien establece con suma claridad la conducta infractora, carece de reglas unánimes sobre el contenido y la determinación del monto del daño $0^{6}$. A esto se suma que la teoría de responsabilidad aplicada se basa sobre el concepto tradicional de propiedad material, la cual difiere del concepto de propiedad intelectual como finalidad y esencia ${ }^{7}$;

\footnotetext{
1 TobÓn Y VARELA (2010), p. 41.
}

${ }^{2}$ Los avances de la tecnología dieron nacimiento a la era digital que consiste en el generalizado uso de Internet y el desarrollo de soportes que permiten almacenar mayor cantidad de información con una calidad mejor que la de los tradicionales. PLAZA (2002), p. 19.

3 Sobre la interacción de la cultura y el mercado en la sociedad de la información CaRBAjo (2009), pp. 55-102.

4 Esteve (2006), p. 208.

${ }^{5}$ Los medios tradicionales involucran soportes físicos para acceder a la obra, como el papel o un casete, en donde se fija; los medios digitales utilizan una red mundial abierta que permite intercambiar información entre los usuarios. LIPSZYC (2004), pp. 245-246.

${ }^{6}$ Se entiende el daño como todo menoscabo o pérdida que una persona sufre en el patrimonio o en sí misma. Pérez (2011), p. 288.

${ }^{7}$ La naturaleza jurídica del derecho de autor tiene por esencia la protección de bienes inmateriales o intangibles, está compuesto por derechos patrimoniales y morales que son inalienables e imprescriptibles, además otorga a los creadores un monopolio legal de explotación económica por un tiempo determinado según estipule la ley. ReNGIFO (2003), p. 33. 
y los avances tecnológicos traen escenarios de infracción al derecho de autor que no se presentan en la propiedad común ${ }^{8}$.

Según la teoría general de la reparación del daño, la determinación del monto del daño crea estándares de conductas en la sociedad que precisan los límites entre lo legal y lo ilegal, desincentiva las infracciones y configura formas para reparar los daños ${ }^{9}$. Por lo anterior, la determinación del monto del daño se convierte en una herramienta útil para resolver los interrogantes aquí planteados, y en general, constituye un aporte al estudio y defensa de los derechos de autor.

El objetivo de este artículo es presentar los resultados de una investigación analítica sobre cómo se determina el monto del daño por infracciones al derecho de autor en el sistema legal colombiano, por medio de una revisión documental de este sistema, en comparación con el de España y Estados Unidos. Lo anterior, con la finalidad de plantear por qué es importante para la responsabilidad civil en infracciones al derecho de autor la valoración del daño, y qué dificultades se presentan a la hora de determinarlo en el entorno digital.

Particularmente, este artículo contribuye al estado del arte contestando a la siguiente pregunta: ¿Qué dificultades se presentan a la hora de determinar el monto del daño en cada una de las infracciones que se producen al derecho de autor en entornos digitales?

\section{Conceptos preliminares}

La siguiente aproximación conceptual del daño y su estudio en el derecho de autor permitirán comprender las dificultades que se presentan al determinar su monto, bajo los supuestos de la propiedad material en sentido tradicional cuando la propiedad intelectual ${ }^{10}$, y por tanto el derecho de autor, son diferentes.

\subsection{El daño según el sistema legal}

Cada sistema legal clasifica y estructura el daño de diferente forma, por ejemplo, el derecho germano-románico o civil lo define como bien jurídico lesionado ${ }^{11}$, mientras que el common law de Estados Unidos utiliza el término

\footnotetext{
${ }^{8}$ Ángel (2005), pp. 2-10.

${ }^{9}$ Ghersi (2007), pp. 15-54.

10 "La propiedad intelectual se relaciona con las creaciones de la mente: invenciones, obras literarias y artísticas, así como símbolos, nombres, e imágenes utilizados en el comercio". Página web de la Organización Mundial de la Propiedad Intelectual (OMPI).

11 Pérez (2011), p. 288.
} 
damage para hacer referencia a la forma como debe compensarse a quien sufrió una pérdida o daño (loss or harm) ${ }^{12}$.

Con relación al daño en el derecho germano-románico (caso de Colombia y España) ${ }^{13}$, este es un elemento de la responsabilidad civil que rige relaciones contractuales y extracontractuales. Se clasifica en daño material y daño moral.

El daño material recae sobre el patrimonio de la persona que lo sufre, generándole una falta de utilidad o beneficio. De este modo, es un daño emergente cuando hay disminución en el patrimonio del afectado, o lucro cesante cuando se deja de percibir ganancias a causa del daño ${ }^{14}$.

El daño moral es aquel que afecta a una persona en asuntos no patrimoniales como la personalidad, creencias, honor, afectos o integridad física ${ }^{15}$. Puede ser moral subjetivo cuando ocasiona un dolor en los sentimientos de la víctima; o moral objetivo cuando, a pesar de ser un daño moral, puede ser apreciable económicamente ${ }^{16}$.

En el common law, el law of torts (derecho de responsabilidad) estudia generalmente la responsabilidad con culpa y cómo debe indemnizarse ante una pérdida o daño (loss and harm) ${ }^{17}$, igualmente observa los costos del daño, denominados damages, que deben pagarse por concepto de tort o responsabilidad. Los damages se dividen en compensatory damages y punitive damages.

Los compensatory damages son la compensación monetaria por un daño en el incumplimiento de un deber. Se dividen en general damages que son compensaciones que se generan, natural y usualmente, como consecuencia del perjuicio causado ${ }^{18}$; también están los special damage ${ }^{19}$ que son todas esas indemnizaciones, no usuales o particulares, resultado del perjuicio, como los gastos médicos generados por el estrés del daño ${ }^{20}$.

Los punitive damages son indemnizaciones que buscan disuadir a quien cometió la conducta culposa para que no la vuelva a realizar, se configura cuando el daño es notoriamente más injusto que en los compensatory damages

\footnotetext{
12 KIONKA (2010), pp. 137-139.

13 El derecho de daños en sistemas jurídicos con influencia del Código francés se estudia el resarcimiento de los daños injustos bajo el título de responsabilidad civil. Roca y NaVArRo (2011), p. 195.

14 Pérez (2011), pp. 299-306.

15 Henao (2011), p. 230.

16 Pérez (2011), pp. 299-307.

17 Corbett (1996), p. 623.

${ }^{18}$ Los más comunes son el lucro cesante, daños a la propiedad y gastos médicos por lesiones físicas.

19 También se conocen como non-economic damages.

${ }^{20}$ KIONKA (2010), p. 349.
} 
y los statutory damages, del mismo modo son una forma de valorar el monto del daño sin probar los perjuicios y/o establecer el monto de los mismos ${ }^{21}$.

Como conclusión, el concepto de daño difiere según cada sistema legal. En el sistema germano-románico el daño es la lesión a un bien jurídico que debe ser reparado, una vez se encuentre acompañado de un nexo causal y una conducta; en cambio, en el common law es la reparación por la lesión a un bien jurídico, por lo cual la conducta y el nexo causal son menos importantes y el menoscabo sólo tiene relevancia en la medida que debe indemnizarse.

\subsection{La obligación de reparar el daño en el derecho de autor}

Países como Estados Unidos han creado su propia regulación para abordar la obligación de reparar el daño al autor/titular de derechos de autor, por esta razón cuenta con una legislación que sólo aplica para copyright; otras legislaciones, como la de Colombia y en algunas ocasiones España, acuden al sistema del derecho común para determinar dicha obligación.

En Colombia, dos preceptos legales presentan la obligación de reparar el daño en derechos de autor. Una es la Decisión Andina 35122, que faculta a las autoridades nacionales, en este caso autoridades judiciales, para que ordenen el pago de una indemnización cuando el autor/titular sufre un daño a su derecho; la otra es la ley $\mathrm{N}^{\circ} 23$ de $1982^{23}$, que acredita a la acción civil como medio para solicitar el resarcimiento del daño o perjuicio causado al derecho de autor ${ }^{24}$. El régimen legal colombiano, a diferencia de la legislación española y estadounidense, no hace distinciones sobre las clases de daños que pueden presentarse,

21 TABв et al. (2005), p. 137.

22 Artículo 57. La autoridad nacional competente, podrá asimismo ordenar lo siguiente:

A) el pago al titular del derecho infringido de una reparación o indemnización adecuada en compensación por los daños y perjuicios sufridos con motivo de la violación de su derecho;

B) que el infractor asuma el pago de las costas del proceso en que haya incurrido el titular del derecho infringido;

C) el retiro definitivo de los canales comerciales, de los ejemplares que constituyan infracción del derecho;

D) las sanciones penales equivalentes a aquellas que se aplican a delitos de similar magnitud.

${ }^{23}$ Artículo 238. La acción civil para el resarcimiento del daño o perjuicio causado por la infracción de esta ley puede ejercerse dentro del proceso penal, o por separado, ante la jurisdicción civil competente, a elección del ofendido.

En el segundo de estos casos, el juicio civil y el penal serán independientes, y la sentencia definitiva que recaiga en uno de ellos no fundará excepción de cosa juzgada en el otro.

24 Plata (2010), p. 157. 
por ejemplo, la valoración del daño moral y el patrimonial es igual, sin embargo el juez al momento de fallar debe tener en cuenta que no son lo mismo.

Siguiendo, Estados Unidos en su Copyright $A c t^{25}$ consagra el deber del infractor de reparar el daño y pagar al autor por las utilidades no obtenidas debido al hecho ilícito. El demandante, según la ley, podrá optar por el resarcimiento de los daños a través de compensatory (actual) damages o statutory damages ${ }^{26}$. Para finalizar, es pertinente decir que las anteriores disposiciones únicamente hacen referencia a los daños con carácter patrimonial.

En España la Ley de propiedad intelectual ${ }^{27}$, en sus artículos 138 y siguientes, consagra la obligación legal de indemnizar los daños ocasionados al derecho de autor, además aclara que el daño puede ser material o moral. Dentro del daño material distingue daño emergente cuando se refiere a la indemnización por el valor de la pérdida que haya sufrido el titular, y lucro cesante cuando obliga al infractor a indemnizar a partir de la ganancia que haya dejado de percibir el titular ${ }^{28}$.

\subsection{Las clases de daño en el derecho de autor}

Tal como se señaló, en el derecho civil el daño puede ser material o moral. El primero hace parte de la esfera económica del daño y el segundo a todos los efectos del detrimento que no se relacionan con el aspecto económico ${ }^{29}$. La anterior clasificación, del daño como bien jurídico lesionado, es la que se utilizará a continuación.

Para desarrollar este ítem del artículo es importante recordar que el derecho de autor en el sistema civil está compuesto por derechos morales ${ }^{30}$ que son las

$25 \S 504$. Remedies for infringement: damages and profits.

(a) In general. -Except as otherwise provided by this title, an infringer of copyright is liable for either

(1) the copyright owner's actual damages and any additional profits of the infringer, as provided by subsection (b); or (2) statutory damages, as provided by subsection (c).

${ }^{26}$ Chesley (2010), pp. 1-36.

27 Artículo 138. Acciones y medidas cautelares urgentes. El titular de los derechos reconocidos en esta ley, sin perjuicio de otras acciones que le correspondan, podrá instar el cese de la actividad ilícita del infractor y exigir la indemnización de los daños materiales y morales causados, en los términos previstos en los artículos 139 y 140 (...).

${ }^{28}$ Cifuentes (2000), p. 89.

29 HeNAO (2011), p. 230.

${ }^{30}$ Aunque los derechos morales no tienen el mismo nivel de protección en los países de common law, el copyright law ha reconocido derechos morales a ciertos creadores con la finalidad de para prevenir la distorsión o alteración de la obra, como por ejemplo el Visual Artists Rights Act (1990) que protege los derechos morales de los artistas visuales. 
prerrogativas, plasmadas en una obra, relacionadas con la personalidad del autor; y derechos patrimoniales referentes a la explotación de la obra ${ }^{31}$.

\section{a) El daño material}

El daño material en el derecho de autor debe: primero, recaer sobre un derecho moral o patrimonial protegido por el derecho de autor, segundo, ser realizado por quien no está autorizado para ello, y tercero afectar el valor de la obra o no permitir obtener de él lo que se esperaba ${ }^{32}$.

Tal como lo señala Nilza ${ }^{33}$, el daño material en el derecho de autor se determina según la pérdida que sufre el titular del derecho de autor, las ganancias que haya dejado de percibir por el daño y los ingresos que llegaron a ser parte del infractor. En ninguno de los casos podrá dejarse de condenar a aquellos infractores, así no exista prueba de alguno de los elementos comunes de responsabilidad o no sea posible determinar el monto del daño ${ }^{34}$.

A modo de ejemplo, si un infractor reprodujo ilícitamente una cantidad de libros y los distribuyó en un país donde el autor no ha explotado los derechos del mismo, o lo divulgó en una página web sin que tenga licenciado el derecho de difusión, al ser juzgado argumentará que, si bien está violando una norma de derecho de autor, las copias ilegales están siendo vendidas en otro país y por tanto no hay existencia del daño así haya nexo causal. El agresor también podrá refutar que dado que el titular de la obra no tenía ninguna expectativa de ingreso por la explotación de la obra por Internet o en otro país, no hay lucro cesante.

Ante el anterior escenario, en Colombia la ley $N^{\circ} 44$ de 1993 en su artículo 57 señala los criterios para determinar los daños materiales causados por el hecho infractor. De manera general son: el valor comercial de los ejemplares producidos o reproducidos sin autorización, el valor que hubiere percibido el titular del derecho de haber autorizado la explotación y el lapso durante el cual se efectuó la explotación ilícita ${ }^{35}$. Estos tres criterios serán explicados con mayor detalle más adelante.

Siguiendo con el análisis del daño material al derecho de autor en Colombia, es significativo señalar que hasta el momento el único precedente judicial en donde se hace una valoración del lucro cesante y daño emergente es la

\footnotetext{
31 PACHÓN (1998), p. 51.

32 Martínez (1996), p. 28.

${ }^{33}$ NILZA (1997), pp. 933-940.

34 Villalba (1997), pp. 947-956.

35 Plata (2010), p. 171.
} 
sentencia del Consejo de Estado número 8968 de $1996^{36}$, que indica que ante toda infracción al derecho de autor se debe indemnizar lo que pudo haber conseguido el titular del derecho de haber explotado la obra de la forma en que lo hizo o pretendía hacerlo el infractor ${ }^{37}$.

El tribunal en este caso decide sobre la acción de reparación directa por falla en el servicio por el uso no autorizado, por parte de la Administración Postal Nacional, de una imagen en estampillas de correo. El Consejo indemniza los perjuicios teniendo en cuenta el valor de las estampillas vendidas y el monto que hubiera obtenido el titular de la obra en caso de haber pactado un contrato de edición con la entidad ${ }^{38}$, desde la fecha de emisión de las estampillas hasta que fue presentada la demanda.

Como última anotación sobre la sentencia, la valoración del daño se basa sobre la existencia de un supuesto contrato de edición, a pesar que la relación entre las partes era extracontractual. Lo anterior revela que el tribunal toma su decisión considerando herramientas de resolución de conflictos del derecho privado ya que recurre a la figura del contrato de edición para contextualizar el caso y resolverlo, sin embargo pudo haber acudido a las directrices que menciona el artículo 57 de la ley No 44 de 1993.

A propósito de los derechos morales, un daño material también puede recaer sobre un derecho de este tipo, en estos escenarios la reparación también debe ser económica ${ }^{39}$, puesto que todas las facultades que integran al derecho de autor no pueden descomponerse y conforman un conjunto que a pesar de ser de diferente naturaleza terminan por estar conectados uno con el otro ${ }^{40}$.

No obstante lo precedido, el sistema civil de Colombia ha desligado las dos clases de derechos de autor ${ }^{41}$, algunos ejemplos se presentan en la diferenciación de derechos que se hace al momento del licenciamiento de una obra y, en

36 "(...) a falta de prueba en contrario, se parte de que las estampillas fueron vendidas en su totalidad entre la fecha de emisión y la de presentación de la demanda y en consecuencia se estima que desde esta última fecha el actor tenía derecho a recibir la suma así liquidada (...)". Consejo de Estado. Sala plena de lo Contencioso Administrativo, sección tercera 11 de marzo de 1996. Magistrado ponente Dr. Juan de Dios Montes, expediente № 8968.

37 Botero (2007), pp. 38-39.

${ }^{38}$ Artículo 106. En todo contrato de edición deberá pactarse el estipendio o regalía que corresponda al autor o titular de la obra. A falta de estipulación, se presumirá que corresponde al autor o titular un $20 \%$ del precio de venta al público de los ejemplares editados.

39 Romero y Santana (2004), pp. 20-45.

40 RodríGuez (1992), pp. 173-174.

${ }^{41}$ Un ejemplo claro es el Código Penal de Colombia en su título VIII, sobre delitos contra los derechos de autor, que hace distinción sobre los delitos que atentan contra los derechos morales y patrimoniales de autor. 
el ámbito criminal, cuando quedan impunes infracciones a derechos morales porque no hay forma de determinar económicamente el monto del daño.

Prosiguiendo con España, la Ley de Propiedad Intelectual, en el artículo $140^{42}$, conceptúa el daño material como la pérdida que haya sufrido el titular, también como lo que se pudo haber llegado a obtener a causa del daño realizado por el infractor, es decir, hace distinción entre el lucro cesante y el daño emergente. En efecto, la Audiencia Provincial de Madrid, en un proceso por infracciones a derechos patrimoniales de autor acepta el daño material como la remuneración que hubiera obtenido el autor de haber utilizado la obra, lo que incluye las ganancias que dejó de ganar el autor y todos los beneficios e ingresos ilegalmente percibidos por el infractor ${ }^{43}$.

La Audiencia para fallar utiliza los mismos elementos para determinar el monto del daño material que el Consejo de Estado en la controversia ocurrida en Colombia, sin embargo, la Audiencia recurrió directamente a las disposiciones de la Ley de Propiedad Intelectual, mientras que el Consejo optó por emplear las reglas de derecho de propiedad material en un sentido tradicional, a pesar de existir la ley $\mathrm{N}^{\circ} 44$ de 1993.

En Estados Unidos, considerando que los damages son la compensación que debe pagarse a quien sufre una lesión a un bien jurídico, el Copyright act no tiene una distinción clara entre daños morales y materiales, pese a esto existe un sistema que permite valorar la compensación del daño, generalmente material, dada la obligación legal de compensar al titular por una lesión.

En el sistema estadounidense la compensación del daño se realiza a partir de las pérdidas y lo que deja de percibir el titular por el perjuicio (compensatory

\footnotetext{
42 Artículo 140. Indemnización.

1. La indemnización por daños y perjuicios debido al titular del derecho infringido comprenderá no sólo el valor de la pérdida que haya sufrido, sino también el de la ganancia que haya dejado de obtener a causa de la violación de su derecho. La cuantía indemnizatoria podrá incluir, en su caso, los gastos de investigación en los que se haya incurrido para obtener pruebas razonables de la comisión de la infracción objeto del procedimiento judicial.
}

2. La indemnización por daños y perjuicios se fijará, a elección del perjudicado, conforme alguno de los criterios siguientes:

A) Las consecuencias económicas negativas, entre ellas la pérdida de beneficios que haya sufrido la parte perjudicada y los beneficios que el infractor haya obtenido por la utilización ilícita. En el caso de daño moral procederá su indemnización, aun no probada la existencia de perjuicio económico. Para su valoración se atenderá a las circunstancias de la infracción, gravedad de la lesión y grado de difusión ilícita de la obra.

B) La cantidad que como remuneración hubiera percibido el perjudicado, si el infractor hubiera pedido autorización para utilizar el derecho de propiedad intelectual en cuestión.

3. La acción para reclamar los daños y perjuicios

${ }_{43}$ Sentencia audiencia provincial de Madrid № 571/2004 de 2004, España. 
damages y demandant's profits). La valoración, en algunos casos se realiza a partir de un sistema de daños preestablecidos que compensa el perjuicio, así no haya pérdida para el demandante o sólo exista ganancia del infractor (statutary damages $)^{44}$.

\section{b) El daño moral}

El daño moral es el menoscabo a la naturaleza de la obra que afecta los intereses del autor en cuanto a su ánimo, imagen, fama o prestigio, por cuanto modifica la forma en que el artista quería que se viera y conociera su obra ${ }^{45}$.

Existe discusión sobre la posibilidad de que un daño moral sea producto de la vulneración de un derecho patrimonial, o si los daños morales sólo están asociados con derechos morales. Según algunos autores, como Antequera, los daños morales siempre estarán ligados a derechos morales del autor, pues el daño moral sólo puede sufrirlo quien ostenta la calidad de autor de la obra, es decir, aquel sobre quien recaen los derechos morales ${ }^{46}$.

Al día de hoy Colombia, en materia civil, no tiene leyes que hagan referencia a la determinación del daño moral en el derecho de autor, sin embargo utiliza la reparación integral ${ }^{47}$ para incluirlos; esta figura indica que todos los daños causados, sin importar su naturaleza, deben ser reparados ${ }^{48}$. Por la inexistencia de fallos que determinen el monto del daño en infracciones al derecho de autor, haciendo una distinción entre los perjuicios por daños morales y patrimoniales, es casi imposible establecer qué apreciación tienen los jueces sobre este tema.

España, en el segundo párrafo del artículo 140 de la Ley de Propiedad Intelectual, indica que el daño moral deberá indemnizarse así no exista un perjuicio económico, y para su valoración se tendrá en cuenta: primero, la circunstancias de la infracción; segundo, la gravedad de la lesión y, tercero, el grado de difusión de la obra. La jurisprudencia española, siguiendo la ley,

${ }^{44}$ Debriyn (2012), pp. 80-110.

45 El daño moral de autor sólo puede sufrirlo quien ostenta la cualidad de tal. El contratante del autor o titular de los derechos podrá sufrir por infracción a derechos económicos, pero nunca al daño moral de autor. MARTínez (1996), p. 54.

46 Antequera (2009), pp. 686-688.

47 Corte Constitucional Sentencia T-269 de 1993. La Corte niega una tutela contra la administración por infracción al derecho de autor: "el actor dispone de otra vía judicial para hacer valer sus pretenciones, como es la ley № 23 de 1982 (...), esta ley contempla una acción breve y sumaria en favor del titular del derecho, la cual viene acompañada de medidas cautelares que son eficientes para satisfacer el derecho invocado por el interesado. En este caso podría recurrir a la acción de reparación directa".

48 Plata (2010), pp. 163-167. 
ha fallado casos en donde existe independencia entre el daño moral y el patrimonial, sin importar los derechos de autor afectados y si existe un perjuicio económico ${ }^{49}$.

En Estados Unidos existe una tendencia a desconocer la compensación a quien sufre una lesión en la esfera moral, por esto generalmente los damages en el copyright no involucran de forma taxativa los daños que no se desprendan de juicios que afectan la esfera económica ${ }^{50}$.

\section{Regulación legal de la determinación del daño en infracciones al derecho de autor}

Puesto que legalmente existe la obligación legal de reparar cualquier daño cuando se vulneran derechos de autor, existen disposiciones en la ley que fijan cómo debe determinarse el monto del daño en infracciones de este tipo.

Los criterios legales de determinación del monto del daño en el derecho de autor en Colombia se encuentran en la ley $N^{\circ} 44$ de $1993^{51}$ y las decisiones de la Comunidad Andina ${ }^{52}$ que expide directrices sobre el tema ${ }^{53}$. El Tratado de Libre Comercio (TLC) firmado con Estados Unidos obliga al país a implementar medidas sobre el sistema de daños en derecho de autor basándose en el sistema anglosajón, estas disposiciones seguramente afectarán los criterios de determinación del daño del derecho de autor que se encuentran en la ley.

En el caso de Estados Unidos, la ley de Copyright establece cómo funciona el sistema de determinación de daños en el Common Law. España, por su lado,

\footnotetext{
${ }^{49}$ Sentencia Audiencia Provincial de Barcelona Núm. 12/2004. El juez en un caso de transformación de una obra musical sin autorización del titular acepta la valoración del daño de manera separada. La determinación del monto del daño se hace respecto al derecho patrimonial de transformación y el derecho moral sobre la modificación o deformación de la obra.

50 Martínez (1996), pp. 41-42.

${ }^{51}$ Artículo $1^{\circ}$.- Los autores de obras literarias, científicas y artísticas gozarán de protección para sus obras en la forma prescrita por la presente ley y, en cuanto fuere compatible con ella, por el derecho común. También protege esta ley a los intérpretes o ejecutantes, a los productores de programas y a los organismos de radiodifusión, en sus derechos conexos a los del autor, en cuanto determina las disposiciones generales para la protección del derecho de autor y permite la remisión al derecho común (leyes civiles, penales y/o administrativas) cuando se requiera.

52 “Qué es la CAN? Somos una comunidad de países autómonos que nos unimos voluntariamente con el objetivo de alcanzar un desarrollo integral, más equilibrado y autónomo, mediante la integración andina, suramericana y latinoamericana. Los países que la integramos-Bolivia, Colombia, Ecuador y Perú- (...)". Página web de la Comunidad Andina de Naciones (CAN).

53 En general, la Decisión 351 de 1993 sobre Derechos de Autor y Derechos Conexos y la Decisión 776 de 2013 Agenda Andina de Ciencia y Tecnología. En desarrollo de este tema, revisar CerdA (2011), pp. 231-282.
} 
fija sus criterios de determinación del daño en la Ley de Propiedad Intelectual y en las directrices de la Unión Europea ${ }^{54}$.

\subsection{Colombia}

La ley $N^{\circ} 44$ de 1993 es el principal referente de la valoración del monto del daño, su artículo $57^{55}$ señala una lista de criterios para determinar los daños materiales causados por un hecho infractor. Los criterios son:

El primero es el valor comercial de los ejemplares producidos o reproducidos sin autorización. Es oportuno mencionar que la valoración se realiza a partir del precio que tienen los ejemplares piratas ${ }^{56}$ y no sobre el que tienen los ejemplares originales, además el monto es medido desde la cantidad de ejemplares existentes y no sobre la cantidad de dinero que obtuvo el infractor ${ }^{57}$. La anterior valoración desconoce el costo de las licencias de derechos económicos de la obra, como el valor comercial de la misma; además olvida que la calidad de la obra original es inferior que la copia ilegal. De esta manera, la valoración es abstracta, ya que no se realiza sobre las utilidades o beneficios percibidos por el infractor. Tal vez la justificación del legislador para esta tendencia es la dificultad de probar la cantidad de copias que se vendieron y que existen al momento del juicio.

El segundo criterio es el valor que hubiere percibido el titular de haber autorizado su explotación. Al parecer el legislador incluye el lucro cesante y delimita de forma amplia el concepto de explotación, previendo las dificultades de determinar el monto del daño en infracciones en entornos digitales.

\footnotetext{
${ }^{54}$ Como, por ejemplo, la Directiva No 2001/29/CEE del Parlamento, de 22 de mayo de 2001, relativa a la armonización de algunos aspectos del derecho de autor en la sociedad de la información, la 2011/77/UE del Parlamento Europeo y del Consejo de 27 de septiembre de 2011 por la que se modifica la directiva 2006/116/CE relativa al plazo de protección del derecho de autor y de determinados derechos afines.

55 Artículo 57.- Para la tasación de los perjuicios materiales causados por el hecho, se tendrá en cuenta: El valor comercial de los ejemplares producidos o reproducidos sin autorización.

El valor que hubiere percibido el titular del derecho de haber autorizado su explotación.

El lapso durante el cual se efectuó la explotación ilícita.

56 "El término 'piratería' abarca la reproducción y distribución de copias de obras protegidas por el derecho de autor, así como su transmisión al público o su puesta a disposición en redes de comunicación en línea, sin la autorización de los propietarios legítimos, cuando dicha autorización resulte necesaria legalmente. La piratería afecta a obras de distintos tipos, como la música, la literatura, el cine, los programas informáticos, los videojuegos, los programas y las señales audiovisuales". Página web de la Organización de las Naciones Unidas para la Educación, la Ciencia y la Cultura (UNESCO).

57 Plata (2010), p. 173.
} 
En el tercer criterio la ley tiene en cuenta el lapso durante el cual se efectuó la explotación ilícita, por lo que quien haya explotado la obra por mayor tiempo será sancionado con mayor severidad. Este criterio le facilita al demandante probar la actividad clandestina ${ }^{58}$.

Hasta el momento no hay precedentes judiciales sobre cómo deben emplearse estos criterios, por tanto, no hay claridad sobre si son de aplicación excluyente o si pueden aplicarse dos o tres al mismo tiempo. Tampoco es claro si el juez, al momento de dirimir una controversia por infracción al derecho de autor, debe tomar en cuenta los derechos vulnerados para escoger alguno de los criterios de valoración del daño o puede escoger a su discreción aquel que cree genere mayores ganancias al demandante.

Del mismo modo, la Decisión Andina 351 de 1993, en el artículo 57, faculta a la autoridad nacional competente a que, dentro de un juicio por vulneración a un derecho de autor, decrete reparación o indemnización adecuada por los daños y perjuicios sufridos; y determine las sanciones penales que se apliquen a delitos de similar magnitud ${ }^{59}$. A pesar de reiterar la obligación del juez de estipular la indemnización al titular/autor por el daño ocasionado, no específica la forma cómo debe determinarse el monto del daño para llegar a indemnizarse.

La ley No 1143 de 4 de julio de 2007, que aprobó el TLC entre Colombia y Estados Unidos ${ }^{60}$ en el capítulo 16, sobre temas comunes de propiedad intelectual, contiene apartes sobre el derecho de autor y derechos conexos que implica variaciones en la indemnización por infracciones al derecho de autor y los criterios de valoración de daños en la ley.

Uno de los segmentos del TLC obliga a las partes a otorgar facultades a las autoridades judiciales para ordenar que el infractor pague al titular por los daños sufridos y las ganancias obtenidas por dicho acto ilegal, que no fueron tomadas en cuenta al calcular la indemnización ${ }^{61}$. Al mismo tiempo se obliga

\footnotetext{
58 Matiz (2002), pp. 3-16.

59 Artículo 57. La autoridad nacional competente, podrá asimismo ordenar lo siguiente:
}

a) El pago al titular del derecho infringido de una reparación o indemnización adecuada en compensación por los daños y perjuicios sufridos con motivo de la violación de su derecho;

b) Que el infractor asuma el pago de las costas del proceso en que haya incurrido el titular del derecho infringido;

c) El retiro definitivo de los canales comerciales, de los ejemplares que constituyan infracción al derecho;

d) Las sanciones penales equivalentes a aquellas que se aplican a delitos de similar magnitud.

60 El Tratado de Libre Comercio entre la República de Colombia y Estados Unidos, sus cartas adjuntas y entendimientos fueron suscritos en Washington, el 22 de noviembre de 2006.

61 Artículo 16.11.7 (a) En los procedimientos judiciales civiles, las autoridades judiciales estarán facultadas para ordenar al infractor que le pague al titular del derecho: 
a los países a crear un sistema de indemnización por daños que considere el valor del bien o el servicio infringido.

En relación con lo anterior, el Tratado de la Organización Mundial del Comercio $(\mathrm{OMC})^{62}$, sobre Aspectos de los Derechos de Propiedad Intelectual relacionados con el Comercio (ADPIC), ratificado en Colombia por la ley N 565 de 2000 en el artículo $45^{63}$, estipula un sistema de determinación del daño, que al parecer cumple con los requerimientos solicitados en el artículo 16.11.7 del TLC; sin embargo, en Colombia no hay sentencias judiciales en donde se utilice esta valoración de perjuicios a pesar de no contradecir la normativa interna.

Adicionalmente, el TLC estipula que las costas procesales y honorarios vayan a cargo de la parte perdedora, lo que ya se encuentra consagrado en los lineamientos procedimentales en materia civil de la Ley colombiana ${ }^{64}$. Por último, pero no menos importante, en el Tratado ${ }^{65}$ las partes se comprometen, en

(i) Una indemnización adecuada para compensar al titular del derecho por los daños sufridos como resultado de la infracción.

(ii) Por lo menos en el caso de infracciones al derecho de autor o derechos conexos, y en el caso de falsificación de marcas, las ganancias obtenidas por el infractor imputables a la infracción y que no fueron tomadas en cuenta al momento de calcular el monto de la indemnización a que se refiere la cláusula (i).

${ }^{62}$ ¿Qué es la OMC? Es la única organización internacional que se ocupa de las normas que rigen el comercio entre los países. Los pilares sobre los que descansa son los acuerdos de la OMC, que han sido negociados y firmados por la gran mayoría de los países que participan en el comercio mundial y ratificados por sus respectivos parlamentos. El objetivo es ayudar a los productores de bienes y servicios, los exportadores y los importadores a llevar adelante sus actividades. Página web de la Organización Mundial del Comercio (OMC).

${ }^{63}$ Artículo 45.-

1. Las autoridades judiciales estarán facultadas para ordenar al infractor que pague al titular del derecho un resarcimiento adecuado para compensar el daño que éste haya sufrido debido a una infracción de su derecho de propiedad intelectual, causada por un infractor que, sabiéndolo o teniendo motivos razonables para saberlo, haya desarrollado una actividad infractora.

2. Las autoridades judiciales estarán asimismo facultadas para ordenar al infractor que pague los gastos del titular del derecho, que pueden incluir los honorarios de los abogados que sean procedentes. Cuando así proceda, los miembros podrán facultar a las autoridades judiciales para que concedan reparación por concepto de beneficios y/o resarcimiento por perjuicios reconocidos previamente, aun cuando el infractor, no sabiéndolo o no teniendo motivos razonables para saberlo, haya desarrollado una actividad infractora.

${ }^{64}$ Artículo 16.11.9 Cada parte dispondrá que sus autoridades judiciales, salvo en circunstancias excepcionales, estarán facultadas para ordenar, a la conclusión del proceso judicial civil respecto a infracciones a los derechos de autor o derechos conexos e infracciones de marcas, que la parte perdedora le pague a la parte ganadora las costas procesales y los honorarios razonables de los abogados.

65 16.11.8 En los procedimientos civiles, cada parte, al menos con respecto a la infracción a los derechos de autor y derechos conexos, y falsificación de marcas, establecerá o mantendrá indemnizaciones preestablecidas, las cuales deberán estar disponibles a elección del titular del derecho como una alternativa a la indemnización basada en daños reales. Dichas indemnizaciones preestablecidas 
procesos civiles por infracciones al derecho de autor, a establecer o mantener ${ }^{66}$ indemnizaciones preestablecidas y determinar los máximos y mínimos en el monto del daño, en caso que el demandante opte por la indemnización según los detrimentos que se prueban dentro del proceso.

Al momento han existido tres iniciativas para regular temas de derecho de autor en el marco del compromiso adquirido con Estados Unidos en el TLC:

El proyecto de ley $N^{\circ} 241$ de 2011 pretendía incentivar a los proveedores de servicio para que disuadieran a quienes almacenaban o transmitían materiales no autorizados para que respetaran los derechos de autor de los titulares, también adicionaba algunos apartes sobre la remoción de contenidos por internet, y ampliaba la pena a quienes publicaran a través de una red digital material protegido por derecho de autor. El proyecto no fue aprobado por el Congreso de la República en su segundo debate ${ }^{67}$.

El segundo proyecto, el 201 de 2012, buscaba regular aspectos sobre medidas tecnológicas como la retransmisión de contenidos en internet, y sancionar a quienes violaran las medidas de seguridad de contenidos protegidos, igualmente proponía nuevas excepciones y limitaciones a los derechos de autor, y facultaba a las autoridades administrativas para conocer de datos personales sin una sentencia judicial. En enero de 2013 la Corte Constitucional lo declaró inexequible por vicios de forma.

Finalmente el tercer proyecto, el 306 del 2013, que versaba sobre los mismos ítems del proyecto anterior, fue archivado cuando se debatía en el Congreso. Como se evidenció, aún no se han presentado iniciativas que de manera directa regulen los compromisos adquiridos por Colombia en el TLC respecto a la determinación del monto del daño.

Así las cosas, según el autor Santiago Bassó68, la falta de elementos probatorios en litigios sobre infracción a derechos de autor o los pocos indicios del daño sufrido en la explotación ilegal de la obra obliga a los jueces a que determinen el monto del daño con parquedad, o que simplemente rechacen el reclamo indemnizatorio. Si el juez a través de las pruebas no logra determinar el monto del daño, debería contar con otra clase de herramientas que le permitan hacer esta evaluación de manera justa.

estarán previstas por la legislación interna y determinadas por las autoridades judiciales, tomando en cuenta los objetivos del sistema de propiedad intelectual, en una cantidad suficiente para compensar al titular del derecho de autor por el daño causado por la infracción y que se constituyan en disuasorios frente a futuras infracciones.

${ }^{66}$ Estados Unidos ya cuenta con un sistema de daños preestablecidos (statutary damages).

${ }^{67}$ CORTES (2013), pp. 1-8.

68 BASSÓ (2011), pp. 159-181. 


\subsection{España}

La legislación española estima la indemnización de los daños a partir del valor comercial de los ejemplares producidos sin autorización del titular y por la remuneración que hubiera percibido el titular en caso de haber autorizado la explotación de la obra. El artículo 140 de la Ley de Propiedad Intelectual consagra que el monto del daño también podrá recaer sobre los beneficios que obtuvo el infractor por la obra ilícita ${ }^{69}$.

Podría inferirse que el legislador busca reparar de manera amplia al titular y evitar que el infractor haga uso de las ganancias que obtuvo a partir de la actividad ilícita. Por los elementos de la responsabilidad civil (conducta, elemento subjetivo y daño) puede ser difícil establecer el elemento subjetivo de la conducta y las ganancias obtenidas, por lo que el juez no sabría el monto del daño por falta de pruebas.

En cuanto a los daños morales, hay obligación de determinarlos aunque no se pruebe o exista un daño económico; la valoración del monto, según el artículo 140 , se realiza sobre las circunstancias en que se produjo la infracción, gravedad de la lesión y grado de difusión ilícita de la obra. La acción para solicitar los daños prescribe en 5 años desde que el interesado pudo ejecutarla, empero la ley no clarifica si dicha prescripción es aplicable en casos de responsabilidad contractual y/o extracontractual.

\subsection{Estados Unidos}

El Copyright consagra varios tipos de valoración del monto del daño para indemnizar las infracciones al derecho de autor. Este es un sistema que además de indemnizar los daños que sufre el titular, incluye las ganancias que obtuvo el infractor con la finalidad de compensar el daño al titular y prevenir que el infractor se beneficie con una actividad ilegal ${ }^{70}$.

La primera valoración son los actual damages ${ }^{71}$, que son los perjuicios sufridos por el titular del derecho cuando ha sido víctima de una infracción.

\footnotetext{
69 Plaza (2002), pp. 142-143.
}

70 El copyright tiene dos propósitos: el cobro de los daños sufridos por el demandante para compensar al titular por las pérdidas consecuencia de la infracción y el cobro de las ganancias obtenidas por el infractor con el fin de prevenir que tenga un beneficio ilegítimo. A pesar de ser propósitos diferentes deben ser calculados de forma conjunta para evitar que se indemnice dos veces. SCHECHTER y THOMAS (2003), p. 194.

71 Caso Andrew Paul Leonard v. Defendant Stemtech Health Sciences, Inc./Stemtech International, Inc. Controversia por el uso, copia y divulgación por internet de fotografías que no fueron registradas ante la oficina de derecho de autor, tomadas por Andrew Paul. El juez otorga una suma de \$1,6 millones por actual damages, sin embargo, el demandante pudo haber obtenido más si hubiera hecho el registro 
En este caso los perjuicios pueden provenir de las pérdidas que sufrió el titular cuando se encuentra compitiendo en el mercado, y de las ganancias que pudo obtener el titular por el licenciamiento en la realización de una obra derivada ${ }^{72}$.

La segunda son los demandant's profits que tasa la indemnización a partir de la presunta ganancia que obtuvo el infractor por la fabricación y venta de la obra, o la divulgación de la misma. En este escenario el demandante también puede buscar la reparación de los daños indirectos con la deducción de los gastos en que incurrió el demandado al producir las copias ilegales y las copias que no se alcanzaron a vender ya que no obtuvo provecho de éstas ${ }^{73}$.

Por último se encuentran los statutory damages ${ }^{74}$, que son una forma de valorar el monto del daño sin probar los perjuicios y/o establecer el monto de los mismos. El demandante en cualquier momento antes del fallo puede acogerse a esta modalidad, sólo debe haber registrado su obra antes de la fecha de la infracción o después de tres meses de publicada la misma ${ }^{75}$.

De la determinación del daño se puede concluir que en el caso de Colombia y España la ley señala explícitamente la obligación de reparar el daño, empero al determinarse falta claridad sobre el sistema de valoración. Particularmente, Colombia remite la valoración del daño en derechos de autor a la responsabilidad civil de la propiedad común, lo que dificulta aún más la tarea para los jueces al momento de dirimir una controversia de este tipo; contrario a Estados Unidos, que posee un sistema de determinación de daños que opera sólo para derechos de autor y en donde en algunas ocasiones la determinación del monto del daño no implica la prueba del mismo.

\section{Problemáticas en la determinación del monto del daño en infracciones al derecho de autor en entornos digitales}

\subsection{Configuración del problema jurídico}

El derecho de autor y la propiedad material son disímiles con relación a objeto, duración y contenido: el derecho de autor recae sobre bienes inmateriales, tiene contenido patrimonial y moral y, además, su duración no es perpetua; por el contrario, la propiedad material está limitada en el tiempo por la ley.

antes. En este caso el Tribunal tomó en consideración lo que hubiera percibido el titular concediendo una licencia.

72 Lafrance (2008), pp. 325-328.

73 Chesley (2010), pp. 1-36.

${ }^{74}$ Caso Bmw of North America, Inc. v. Gore. Sobre los límites de statutory damage: El tribunal mide el grado de reproche de la conducta del demandado, la razonabilidad entre los daños reales y su compensación, además revisa los precedentes de las sanciones penales por conductas similares.

75 SCheChter y ThOMAs (2003), p. 198. 
Debido a que la protección del derecho de autor versa sobre derechos diferentes, se han creado normas e instituciones propias, pues sería un error tratar igual a lo que es diferente. Dentro de las leyes del derecho de autor, por la importancia de proteger la obra y al titular, hay disposiciones referidas al deber de reparar cualquier daño que se ocasione cuando se vulneran derechos del titular de la obra.

A pesar de la obligación legal de indemnizar los perjuicios por infracciones al derecho de autor, la ley señala de manera general y sin tener en cuenta las particularidades del derecho de autor, cómo debe determinarse el monto del daño. En los entornos digitales, que proveen dinámicas de explotación de derechos de autor innovadoras y cambiantes, cuando ocurren infracciones al derecho de autor se dificulta comprobar la responsabilidad del infractor, ya que no hay claridad sobre el momento y lugar donde ocurrió la conducta; particularmente, para determinar el daño es complicado valorar el monto pues generalmente en una sola infracción se pueden vulnerar varios derechos de autor, lo que obstaculiza que se prueben los perjuicios. Es así como el propósito de esta investigación es establecer criterios de determinación del monto del daño en entornos digitales.

\subsection{Análisis del problema jurídico}

Gracias a los avances de la tecnología hoy en día existen nuevas formas de acceder y adquirir información. Como consecuencia de estos avances el intercambio de archivos musicales y audiovisuales a través del Internet es mucho más fácil y menos costoso; se pueden realizar operaciones para compartir información almacenada, en cualquier aparato electrónico, por medio de un software; se ha masificado el acceso a la educación, la cultura y el arte con la aparición del acceso abierto ${ }^{76}$; y hay mayor exposición de información a través de las redes como Facebook o Instagram.

En el caso de las infracciones al derecho de autor, estas nuevas dinámicas tecnológicas no pueden equipararse el derecho de la propiedad material en sentido tradicional, pues la evaluación de estas conductas infractoras ${ }^{77}$ es más

\footnotetext{
76 "El acceso abierto indica la posibilidad de utilizar recursos digitales tales como datos, resultados de producción científica, material educativo o manifestaciones culturales, sin pago alguno, por instrumentos tecnológicos (interoperables y en formatos estándares que varían según los requerimientos que se van construyendo o desarrollando para cada tipo de recurso) que adicionalmente cuentan con los permisos o características legales que consienten su publicación y circulación en la red". ARENCIBIA (2006), p. 3.

77 La mayoría de infracciones al derecho de autor que ocurren en entornos digitales se relacionan con: primero, la ilicitud en la difusión de contenidos protegidos por derecho de autor y las condiciones como se efectúan; segundo, el pago en las remuneraciones originadas por las repetitivas explotaciones de la obra; por último, las responsabilidades en el flujo de la información protegida. LIPSZYC (2004), p. 246.
} 
compleja. En efecto, existen dificultades debido a que los daños son sucesivos y recaen sobre varios derechos en cabeza de un solo autor y/o titular; además, la mayoría de veces su delimitación temporal y espacial es indeterminable, lo que obstaculiza valorar el monto del daño.

Ahondando en el tema de la responsabilidad civil en infracciones al derecho de autor en entornos digitales, la autora Lipszyc ${ }^{78}$ señala que el presupuesto de responsabilidad civil será el mismo que en el derecho común: demostrar el detrimento, la antijuricidad y el nexo causal; la valoración del daño se realiza bajo las mismas reglas del derecho de autor en medios tradicionales.

Ejemplificando, en un proceso por comunicación pública ilegal de una obra teatral en una página de Internet el juez, en concordancia con la ley, aceptará como daño la remuneración que recibiría el titular si hubiera autorizado la exploración de la obra por ese medio, o según las ganancias que obtuvieron los infractores. En este evento la determinación del monto del daño tiene en cuenta la pérdida del titular, como las ganancias dejadas de percibir.

Es posible que la comunicación haya sido gratuita y que el infractor no haya generado ingresos, aquí el juez tendrá dificultades para valorar el monto de los daños patrimoniales y morales porque no hay existencia económica de ellos. Aquí, el infractor directamente no concibió ingresos y no es posible saber el valor que hubiere ganado el titular de haber autorizado la comunicación.

Siguiendo con la obra teatral: Si cada usuario hubiera pagado una suscripción a la página web para ver la obra, el lucro cesante podría estimarse por el valor que hubiese obtenido el titular al autorizar la comunicación; este valor podría no ser el mismo que percibió el infractor por la suscripción de los usuarios y tal vez los que se suscribieron lo hicieron por otras razones. En todo caso, probar cualquiera de los imaginarios para determinar el monto del daño es complicado.

El juez para hacer la valoración del monto del daño tendrá que tener en cuenta otras "circunstancias", como la cantidad de personas que vieron la obra por el medio que tenía licencia para transmitirlo (canal de tv o página de Internet) y/o las personas que la vieron a través de la página sin licencia. Todos estos posibles criterios para valorar el daño, son supuestos que serán discrecionales al juez pues no existen parámetros legales que dirijan su decisión.

Sobre a quién es atribuible el daño existen varias posturas, unas rechazan la responsabilidad y otras optan por la reversión de la carga de las pruebas. Según Esteve ${ }^{79}$, el titular de los derechos de autor puede demandar a quien haya cometido directamente la infracción, al proveedor de servicios de Internet

${ }^{78}$ El resarcimiento del daño en países donde la valoración proviene del derecho común. LIPSZYC (2004), p. 383.

${ }^{79}$ Esteve (2006), pp. 208-209. 
donde se alojan los contenidos ilícitos o los intermediarios que permitan que se cometan las infracciones. Si el demandante prueba la responsabilidad de todos aquellos a quienes demandó, el juez tendrá la tarea de valorar el daño sobre las ganancias que obtuvieron los infractores al reproducir la obra sin autorización o sobre el valor que hubiere percibido el titular del derecho de haber autorizado su explotación ${ }^{80}$.

Desarrollando lo precedido, cuando un proveedor de contenido no tiene la autorización para reproducir una obra, es clara su responsabilidad ${ }^{81}$. En este escenario, según la ley, la determinación del daño se realizará a partir del valor que obtuvo el infractor al reproducir la obra sin autorización ¿Pero qué pasa si la distribución y reproducción de la obra se realizó gratuitamente? ¿Podrá el juez fallar según el valor comercial de la obra, contradiciendo el artículo 57 de la ley $N^{\circ} 44$ ? ¿Tendrá que considerar los rubros que hubiere percibido el titular de derecho de haber autorizado su explotación y el tiempo de la explotación? En cualquiera de las opciones, el reto se encuentra en probar los anteriores imaginarios.

La situación se complica cuando los contenidos son provistos por terceros y el autor perjudicado sólo advierte al proveedor de servicios en línea sobre la infracción. Al momento del juicio, el demandante deberá probar la no diligencia y descuido de los proveedores frente a las actuaciones de sus clientes y suscriptores, en caso que no sea posible, el juez no tendrá herramientas para cuantificar el daño porque no hay claridad sobre quién es responsable por la infracción ${ }^{82}$.

Los presupuestos antes nombrados son sólo algunos de los inconvenientes que pueden resultar de la determinación del monto del daño en infracciones al derecho de autor en Internet, en el régimen legal colombiano. En comparación con la legislación española, la Ley de Propiedad Intelectual posee mayores herramientas al momento de determinar el daño ya que fija la valoración tanto de daños morales como patrimoniales, lo que da mayores instrumentos al juez para fallar.

El sistema de daños preestablecidos del copyright parece ser una solución para valorar el monto del daño en infracciones al derecho de autor en entornos digitales, luego que podría asegurar la indemnización en infracciones que carecen de prueba o de existencia de perjuicios. Por las particularidades del derecho de autor en entorno digital y considerando las diferencias legales y económicas de Estados Unidos respecto a Colombia, el sistema de daños preestablecidos

${ }^{80}$ Revisar supuestos de la ley № 44 de 1993.

${ }^{81}$ LIPSZYC (2004), pp. 354-355.

82 Ríos (2009), pp. 553-554. 
del copyright debe adecuarse de tal forma que ayude a equilibrar el acceso a las obras y la explotación de las mismas sin desconocer los derechos de los autores y usuarios.

\section{Conclusiones}

Los criterios de determinación del monto del daño crean estándares de conducta que indican cuándo se está frente a una infracción y cuál es la indemnización al cometerse dicho ilícito, de ahí que desestimula que se cometan estos actos y, que en caso de cometerse, realmente se compense el daño. Luego, la determinación del monto del daño mejoraría la transferencia de derechos de autor, concebiría más y mejores formas de fijar y acceder a las obras, lo cual genera mayor reconocimiento al autor y más goce de la cultura y educación por parte de la sociedad.

En lo que respecta a los sistemas de determinación del monto del daño de los países en estudio, se establece que existen divergencias en sus regulaciones legales. Por ejemplo: Estados Unidos, al proteger de manera mayoritaria los derechos patrimoniales, tiene en su sistema de responsabilidad, entre otros asuntos, la figura de daños preestablecidos que asegura una reparación del daño así no se pruebe el mismo, pues la finalidad del copyright es enfatizar en la obligación de resarcir el daño e incentivar que la conducta infractora no se repita.

A diferencia del sistema anglosajón, los ordenamientos jurídicos basados en el derecho civil propenden a la protección e institucionalización del derecho moral, lo que amplía el espectro de protección del derecho de autor. En el caso de España, existe una regulación más desarrollada que establece los parámetros para la valoración del daño, tanto moral como material, en el derecho de autor; en cambio Colombia sólo regula los daños materiales a pesar del reconocimiento de los daños morales en el derecho de autor.

En entornos digitales, el análisis demuestra la necesidad de regular la determinación del monto del daño en infracciones al derecho de autor, debido a las dificultades para fijar qué derechos fueron vulnerados, asimismo cómo y cuándo se cometió la infracción. A propósito de la legislación colombiana, la falta de un sistema de determinación del monto del daño en Internet ha dejado a los jueces sin herramientas legales para fallar y a los usuarios escépticos sobre la legitimidad de las indemnizaciones en las sentencias, lo cual se evidencia en la poca jurisprudencia que existe al respecto.

De este modo, la determinación del monto del daño en entornos digitales debería: primero, ser discrecional del juez tomando en cuenta los límites legales que proponga el sistema, así siempre tendrá directrices para actuar en pro de los fines propios del derecho de autor. Segundo, permitir al demandante optar por la determinación de daños preestablecidos para lograr mejor uso de los recursos legales y alertar a los usuarios sobre las sanciones por cometer estas 
infracciones. Por último, prever la indemnización de derechos, tanto patrimoniales como morales, en caso que sea posible.

Los resultados de este trabajo invitan a promover cambios en el sistema de derecho de autor, en particular sobre la forma como se viene estableciendo la determinación del daño en esta clase de infracciones con el propósito de lograr que se respeten los derechos de los autores y titulares; y se facilite la circulación legal de contenidos. En el caso de los entornos digitales, que prevé dinámicas de explotación de derechos de autor innovadoras y cambiantes, el reto con la valoración del monto del daño es estipular un sistema de indemnización justa que asegure la transferencia legal de información.

\section{BiBLIOGRAFÍA CITADA}

ÁNGEL, Miguel (2005): "La indemnización de los daños causados a los derechos de propiedad intelectual sobre la obra", en: AA.VV., Seminario sobre la obra individual: creación, producción y explotación (Buenos Aires, Organización Mundial de la Propiedad Intelectual), pp. 2-10.

ANTEQUeRA, Ricardo (2009): Estudios de derecho industrial y derecho de autor (Análisis de jurisprudencia comparada) (Bogotá, Pontificia Universidad Javeriana).

ARENCIBIA, Jorge (2006): "Las iniciativas para el acceso abierto a la información científica en el contexto de la web semántica", en: Biblios: Revista electrónica de bibliotecología, archivología y museología (Volumen VII, № 25-26), pp. 1-14.

BASSÓ, Santiago (2011): "La presunción jurisprudencial de responsabilidad por daños a la propiedad intelectual" en: AA.VV., Derechos intelectuales N N 16, Colección de ASIPI (Bogotá, Legis), pp. 159-181.

Botero, Luis Felipe (2007): "La indemnización de perjuicios en las acciones de infracción a los derechos de propiedad intelectual", en: Revista de Propiedad Inmaterial ( $\left.\mathrm{N}^{\circ} 11\right)$, pp. 23-44.

Carbajo, Fernando (2009): "Aspectos jurídicos del conocimiento libre. Propiedad intelectual y acceso a la información", en: AA.VV., Dominio abierto. Conocimiento libre y cooperación (Madrid, Ediciones Ciencias Sociales), pp. 54-102.

Cerda, Alberto (2011): "Armonización de los derechos de autor en la Comunidad Andina: hacia un nuevo régimen común" en: Revista lus et Praxis (Volumen XVII, No 2), pp. 231-282.

ChesLeY, Karen (2010): "Calculating damage under the digital millennium copyright act: how far should courts go when multiplying statutory awards?", en: Journal of the copyright society of the U.S.A. (Winter, № 57), pp. 1-36. 
Cifuentes, Santos (2000): "Los daños en materia de propiedad intelectual", en: II Seminario Nacional para la Difusión del Derecho de Autor y la Propiedad Intelectual. Disponible en: http://www.cadra.org.ar/upload/Cifuentes_Danos_Propiedad_Intelectual.pdf [visitado el 28/02/2014].

Corbett, Angus (1996): "The (self) Regulation of law: A synergistic model of Tort Law and regulation", en: University of New south Wales Law Journal (Volumen XXV), pp. 616-650.

Comunidad Andina: "¿Qué es la CAN?" Disponible en: http://www.comunidadandina.org/quienes.aspx [visitado el 20/01/2014].

CORTÉs, Carlos (2013): "El debate pendiente en Colombia sobre la protección de derechos de autor en internet. El caso de la Ley Lleras", en: Dokumentos, para aportar a la discusión ( $\left.\mathrm{N}^{\mathrm{o}} 1\right)$. Disponible en: http://karisma.org. co/wp-content/uploads/2013/04/paper1 elcasoleylleras.pdf [visitado el 12/29/2013].

DeBRIYN, James (2012): "Shedding light on copyright trolls: an analysis of mass copyright litigation in the age of statutory damages", en: UCLA Entertainment Law Review (No 19-1), pp. 80-110.

Dirección Nacional de Derecho de Autor: "Definición". Disponible en: http:// www.derechodeautor.gov.co/web/guest/definicion_[visitado el 12/20/2013].

Esteve, Lydia (2006): Aspectos internacionales de las infracciones de derechos de autor en Internet (Granada, Editorial Comares).

GHeRsI, Carlos (2013): Teoría general de la reparación de daños, Tercera edición (Buenos Aires, Astrea).

HenAo, Juan Carlos (2007): El daño. Análisis comparado de la responsabilidad extracontractual del Estado en derecho colombiano y francés (Bogotá, Universidad Externado de Colombia).

KıONKA, Edward (2010): Tort in a nutshell, Novena edición (Toronto, Thomson Reuters).

KosKInEN-OlsSON, Tarja (2008): "La gestión de los derechos de autor en el entorno digital", en: Revista Iberoamericana de Derecho de Autor (Año II, № 3, enero-junio) pp. 36-61.

LAFRANCE, Mary (2008): Copyright law in a nutshell (Boston, Thomson Reuters).

LIPSZYC, Delia (2004): Nuevos temas de derecho de autor y derechos conexos (Buenos aires, Ediciones UNESCO/CERLALC/ZAVALIA).

MARTínez, Pascual (1996): El daño moral contractual en la ley de propiedad intelectual (Madrid,Tecnos).

Matız, Carlos (2002): "Delitos contra los derechos de autor en el nuevo Código penal (ley No 599 de 2001)", en: Revista La Propiedad Inmaterial (№ 5), pp. 3-16. 
NıızA, Salvo (1997): "Infracciones y sanciones civiles. 110 años de protección internacional del derecho de autor: Berna 1886-Ginebra 1996", en: AA.VV., III Congreso Iberoamericano sobre Derecho de Autor y Derechos Conexos (Madrid, OMPI), pp. 933-940.

Organización Mundial de la Propiedad Intelectual: “¿Qué es la propiedad intelectual". Disponible en: http://www.wipo.int/about-ip/es/ [visitado el $1 / 12 / 2014]$.

Organización Mundial del Comercio: “¿Qué es la OMC?". Disponible en: http://www.wto.org/spanish/thewto_s/whatis_s/whatis_s.htm [visitado el $1 / 12 / 2014]$.

PACHón, Manuel (1998): Manual de derechos de autor (Bogotá, Temis).

Pérez, Álvaro (2011): Teoría general de las obligaciones (Santiago de Chile, Ediciones doctrina y Ley Ltda.), Volumen II.

PlatA, Luis Carlos (2010): Responsabilidad civil por infracciones al derecho de autor (Bogotá, Ibáñez).

PlazA, Javier (2002): Propiedad intelectual y sociedad de la información (Valencia, Aranzadi).

Rengifo, Ernesto (2003): Propiedad intelectual, el moderno derecho de autor (Bogotá, Universidad Externado de Colombia).

Ríos, Wilson (2009): La propiedad intelectual en la era de las tecnologías de información y comunicaciones (Bogotá, Universidad de los Andes).

Roca, Encarna y NavarRo, Mónica (2011): Derecho de daños. Textos y materiales, sexta edición (Valencia, Tirant lo Blanch).

Rodríguez, José Miguel (1992): La cesión en exclusiva de los derechos de autor (Madrid, Centro de Estudios Ramón Areces S.A.).

Romero, Ania y Santana, María Amparo (2004): "Consideraciones sobre la valoracion del daño moral en el derecho de autor", en: Revista Cubana de Derecho (No 23-24), pp. 20-45.

SCHECHTER, Roger y THOMAS, John (2003): Intellectual property, the law of Copyrights, patents and trademarks (Washington, Tomson West).

TAвB, William; Shoben, Elaine y O'Connell, John (2005): Remedies In a Nutshell, tercera edición (St. Paul, Thomson West).

ToBón, Natalia y VARelA, Eduardo (2010): Derecho de autor para creativos (Bogotá, lbáñez).

UNESCO: “¿Qué es la piratería?”. Disponible en: http://portal.unesco.org/culture/ es/ev.php-URL_ID=39397\&URL_DO=DO_TOPIC\&URL_SECTION=201. html [visitado el 01/12/2014].

Velásquez, Obdulio (2009): Responsabilidad civil extracontractual (Bogotá, Universidad de La Sabana). 
Villalba, Carlos (1997): "Infracciones y sanciones en el derecho de autor y derechos conexos. La evaluación del daño. 110 años de protección internacional del derecho de autor: Berna 1886-Ginebra 1996", en: AA.VV., III Congreso Iberoamericano sobre derecho de autor y derechos conexos (Madrid, OMPI), pp. 947-956.

\section{NORMAS JURÍDICAS CITADAS}

Visual Artists rights act (VARA) de 1990.

Tratado sobre Aspectos de los Derechos de Propiedad Intelectual relacionados con el Comercio (ADPIC). 15 de abril de 1994.

Decisión Andina 351. 17 de diciembre de 1993.

Decisión Andina 776. 16 de noviembre de 2012.

Directiva 2012/28/UE del Parlamento Europeo y del Consejo, sobre ciertos usos autorizados de las obras huérfanas. 25 de octubre de 2012.

Directiva 2011/77/UE del Parlamento Europeo y del Consejo, por la que se modifica la Directiva 2006/116/CE relativa al plazo de protección del derecho de autor y de determinados derechos afines. 27 de septiembre de 2011.

Directiva 2001/29/CEE del Parlamento, relativa a la armonización de algunos aspectos del derecho de autor en la sociedad de la información. 22 de mayo de 2001.

Ley N $N^{\circ} 23$ de Colombia, sobre Derechos de Autor. 28 de enero de 1982.

Ley $\mathrm{N}^{\circ} 44$ de Colombia, por la cual se modifica y adiciona la ley $\mathrm{N}^{\circ} 23$ de 1982 y se modifica la ley № 29 de 1944. 5 de febrero de 1993.

Ley $N^{\circ} 565$ de Colombia, por medio de la cual se aprueba el Tratado de la Ompi sobre derechos de autor (WCT) adoptado en Ginebra. 2 de febrero de 2000.

Ley $\mathrm{N}^{\circ} 1143$ de Colombia, por medio de la cual se aprueba el Acuerdo de promoción comercial entre la República de Colombia y los Estados Unidos de América, sus cartas adjuntas y sus entendimientos, suscritos en Washington el 22 de noviembre de 2006. 4 de julio de 2007.

Real decreto legislativo 1/1996, Ley de Propiedad Intelectual de España. 12 de abril de 1996.

Proyecto de ley $\mathrm{N}^{\circ} 241$ de Colombia, por la cual se regula la responsabilidad por las infracciones al derecho de autor y los derechos conexos en Internet. 4 de abril de 2011.

Proyecto de ley $\mathrm{N}^{\circ} 201$ de Colombia, por la cual se regula la responsabilidad por las infracciones al derecho de autor y los derechos conexos en internet. 20 de marzo de 2012.

Proyecto de ley $\mathrm{N}^{\circ} 001$ de Colombia, por medio de la cual se establecen limitaciones y excepciones al Derecho de Autor. 20 de julio de 2012. 
Proyecto de ley $\mathrm{N}^{\circ} 306$ de Colombia, por la cual se modifica la Ley $\mathrm{N}^{\circ} 23$ de 1982 y se adiciona la legislación nacional en materia de derecho de autor y derechos conexos, 15 de mayo de 2013.

JURISPRUDENCIA CITADA

Caso Bmw Of North America, Inc. V. Gore, US559 (1996) de Estados Unidos.

Caso Andrew Paul Leonard V. Defendant Stemtech Health Sciences, Inc./Stemtech International, Inc., Civil Action No 08-067-LPS-CJB (2011) de Estados Unidos.

Consejo de Estado. Sala penal de lo contencioso administrativo, sección tercera 11 de marzo de 1996. Magistrado ponente: Dr. Juan de Dios Montes (Exp. 8968) de Colombia.

Sentencia Audiencia Provincial de Barcelona No 12/2004 de España.

Sentencia Audiencia Provincial de Madrid № 571/2004 de España.

Corte Constitucional. Sala plena Sentencia. Magistrado sustanciador: Vladimiro Naranjo. (T-269 de 1993) de Colombia. 